\title{
O PROBLEMA DA MULTIPLICIDADE POLÍTICA PARA O MATERIALISMO HISTÓRICO: AS ANÁLISES DOS SISTEMAS-MUNDO E O DESENVOLVIMENTO DESIGUAL E COMBINADO ${ }^{1}$
}

Felipe Antunes de Oliveira ${ }^{2}$

\section{Resumo}

As análises dos sistemas-mundo e a teoria do desenvolvimento desigual e combinado representam duas das mais interessantes e inovadoras perspectivas teóricas para o estudo da economia política internacional baseadas no programa de pesquisa materialista histórico. Nos textos basilares de ambas as perspectivas, Trotsky e Wallerstein se defrontaram com o mesmo problema: como superar visões etapistas do desenvolvimento, derivadas do "marxismo vulgar", que previa a impossibilidade do surgimento de revoluções socialistas em países cujo nível de desenvolvimento fosse atrasado em relação aos Estados capitalistas centrais. Por caminhos diferentes, Trotsky e Wallerstein rompem com essa visão. Trotsky sugere o caráter desigual e combinado dos modos de produção em países atrasados; Wallerstein propõe uma perspectiva holística, em que os modos de produção aparecessem com referência à economia-mundo. Em ambos os casos, é possível identificar o problema subjacente causado pelo fato da multiplicidade política, pois o capitalismo efetivamente não se espalhou de modo igual por diferentes Estados. No presente artigo, argumenta-se que, apesar substanciais diferenças que apresentam entre si, as contribuições de Trotsky e Wallerstein podem ser vistas como complementares, ampliando o poder explicativo do materialismo histórico.

Palavras-Chave: Desenvolvimento Desigual e Combinado - Revolução Permanente - Sistemas-mundo - Economia-mundo - Materialismo Histórico - Etapismo - León Trotsky - Immanuel Wallerstein.

Classificação JEL: F59; B51

Artigo original preparado para o VIII Colóquio Brasileiro em Economia Política dos Sistemas-Mundo.

Doutorando em Relações Internacionais - Universidade de Sussex, Mestre em Diplomacia - Instituto Rio Branco, Bacharel em História - Universidade Federal do Rio de Janeiro. E-mail: antunes.1984@gmail.com 


\section{INTRODUÇÃO - O MESMO PROBLEMA, DOIS CAMINHOS}

León Trotsky e Immanuel Wallerstein produziram, em momentos e contextos bastante distintos, duas das mais importantes contribuições ao pensamento materialista histórico no século XX. O primeiro, ao postular o caráter necessariamente desigual e combinado dos processos de desenvolvimento nacionais e ao definir com clareza a necessidade de que momentos revolucionários tornem-se revoluções permanentes; e o segundo, ao identificar o nível de análise mais adequado para o entendimento das transformações materiais dos modos de produção, ampliaram significativamente o poder explicativo do materialismo histórico, apontando caminhos para a aplicação dos conceitos fundamentais formuladas por Karl Marx à realidade internacional, caracterizada pela multiplicidade política sistematicamente relacionada.

Ambos partem do mesmo problema - a inadequação das análises nacionais etapistas, baseadas no que Trotsky chama de "marxismo vulgar" (Trotsky, 2011: XXXIII), para explicar o desenvolvimento econômico e social dos Estados nos quais a acumulação de capital atingiu níveis inferiores àqueles observados no centro do capitalismo global. Especificamente, Trotsky demonstra como a revolução socialista poderia se dar na Rússia, cujas estruturas produtiva e social atrasadas em relação à Europa Ocidental supostamente fariam do país um lugar pouco propício à superação do capitalismo; enquanto Wallerstein argumenta de modo firme contra a ideia de que as revoluções na América Latina deveriam passar antes pela fase burguesa, superando os traços de feudalismo que alguns acreditavam ainda existir na região, para apenas então tornar possível revoluções realmente socialistas.

Embora os pontos de partida de Trotsky e Wallerstein sejam próximos, os argumentos apresentados por cada autor contra a ideia de que a crise terminal do sistema capitalista deveria surgir necessariamente e em primeiro lugar no centro do capitalismo global - ou seja, nos Estados desenvolvidos - são sensivelmente diferentes, e iluminam aspectos bastante distintos das relações internacionais no mundo contemporâneo. O objetivo desse breve artigo é mostrar como a teoria do desenvolvimento desigual e combinado e a análise dos sistemas-mundo, longe de serem perspectivas excludentes, podem complementar-se em uma síntese capaz de expandir os postulados 
do materialismo histórico e ampliar seu poder explicativo. Não se trata, evidentemente, de sugerir que ambas as perspectivas teóricas analisadas se sobrepõe, tampouco de obliterar as importantes diferenças entre elas. $\mathrm{O}$ que se sugere é a possibilidade de um diálogo construtivo entre essas duas tradições críticas da economia política internacional.

$\mathrm{O}$ artigo está dividido em três partes, além dessa introdução. Na primeira, são apresentados de modo esquemático os principais elementos da teoria do desenvolvimento desigual e combinado, bem como análises recentes, que procuram colocar as ideias de Trotsky no centro de uma nova teoria geral das relações internacionais. Em seguida, será delineada a perspectiva de análise do sistema mundo, tomando como base o seminal artigo The Rise and Future Demise of the Wolrd Capitalist System, Concepts for a Comparative Analysis, publicado por Wallerstein em 1974, mas recorrendo também a outros escritos do autor. Ainda na segunda seção, são indicados dois pontos de contato nos quais a teoria do desenvolvimento desigual e combinado e as análises dos sistemas-mundo podem ser utilizadas para complementar importantes aspectos problemáticos que surgem em ambas as perspectiva teórica. Por fim, procura-se mostrar que Trotsky e Wallerstein apresentaram contribuições relevantes ao "programa de pesquisa" materialista histórico, estendendo-o significativamente. $\mathrm{O}$ artigo termina com uma tentativa de síntese dos postulados fundamentais do materialismo histórico enriquecido com as contribuições de Trotsky e Wallerstein, de modo a incluir a multiplicidade política, ou seja, a existência de diversos Estados, cujas relações de cooperação e competição definem as possibilidades de transformações sistêmicas nos meios de produção.

Desde já, é importante deixar claro que não se tem a pretensão de esgotar os diversos aspectos da vasta obra de Wallerstein ou de Trotsky. De modo muito mais modesto, considera-se que esse artigo já terá excedido as expectativas do autor se apontar para elementos fundamentais das ideias dos dois pensadores que vêm sendo negligenciados mutuamente por estudiosos que trabalham com a perspectiva teórica dos sistemas-mundo ou do desenvolvimento desigual e combinado, incentivando assim o diálogo entre duas das mais dinâmicas e ricas correntes críticas da economia política internacional. 


\title{
2. TROTSKY - DESENVOLVIMENTO DESIGUAL E COMBINADO
}

\begin{abstract}
As leis da história nada têm em comum com o esquematismo pedante. A desigualdade, a lei mais geral do processo histórico, revela-se de modo mais agudo e complexo no destino dos países atrasados. Sob o chicote da necessidade externa, a sua cultura atrasada é compelida a dar saltos. Da lei universal da desigualdade deriva-se outra lei a qual, por falta de nome melhor, podemos chamar de desenvolvimento combinado pelo que nos referimos à junção dos diferentes estágios da jornada, uma combinação dos diferentes passos, um amálgama de formas arcaicas com outras mais contemporâneas. Sem essa lei, que deve ser tomada, evidentemente, em seu inteiro conteúdo material, é impossível entender a história da Rússia, e, na verdade, de qualquer país de segunda, terceira ou décima classe cultural. (Trotsky, 2008: 5)
\end{abstract}

A ideia apresentada com clareza por Trotsky nesse sempre citado parágrafo de sua monumental História da Revolução Russa, cuja primeira edição foi lançada em 1931, já estava presente em forma embrionária em escritos anteriores, notadamente no primeiro capítulo do panfleto em $\mathrm{Ba}$ lanços e Perspectivas, publicado em 1906. O ponto fundamental levantado pelo autor, cujas consequências práticas são evidentes para a projeção da possibilidade da revolução socialista na Rússia - então sua maior preocupação -, é que a evolução material dos meios de produção não segue uma linha reta, definida por estágios necessários e universais, pelos quais todos os Estados nacionais deveriam passar.

A leitura reducionista do materialismo histórico encontra cinco tipos básicos de modos de produção: o comunismo primitivo, a escravidão, o feudalismo, o capitalismo e o socialismo. Este esquematismo, apresentado, por exemplo, por Stalin em Sobre o materialismo dialético e o materialismo histórico, publicado em 1938, embora mal adequado à experiência histórica da própria Revolução Russa, influenciou lideranças de diversos partidos comunistas, que, ao identificarem as estruturas produtivas dos países na periferia do capitalismo global como pré-capitalista, postularam a necessidade de revoluções nacionais de caráter burguês-capitalista como etapa anterior a revoluções socialistas. 
O conceito de desenvolvimento desigual e combinado representa, assim, uma inovação teórica, pois rompe com o pressuposto, nem sempre explicitado pelas visões etapistas, de que as sociedades evoluem de forma autóctone, devendo passar individualmente pelos mesmos estágios definidos e necessários. Ao destacar o papel do "chicote da necessidade externa", Trotsky aponta para o fato de que, desde de sempre, a evolução material das sociedade se dá em interações - na maior parte das vezes conflituosas com outras sociedades. Em um esforço de síntese, o argumento de Trotsky poderia ser estruturado, em termos gerais, nos seguintes passos:

1) A transformação material das forças produtivas de diferentes sociedades se dá em tempos históricos diferentes (“desigualdade" como a lei geral do desenvolvimento).

2) As sociedades cujas forças produtivas desenvolvem-se mais rápido exercem pressões materiais sobre as sociedades atrasadas ("chicote da necessidade externa").

3) As estruturas de produção das sociedades atrasadas reagem dialeticamente à pressão externa, desenvolvendo-se ("privilégio do atraso histórico") 3 .

4) A forma como esse desenvolvimento se dá influencia e é influenciada pela estrutura interna de cada sociedade (“desenvolvimento combinado").

5) Como corolário, pode-se acrescentar que, ao transformar-se, a sociedade atrasada altera sua relação com a sociedade desenvolvida, afetando a estrutura global das relações de produção e de poder.

Recentemente, esse já clássico conceito de Trotsky, cujo uso acadêmico sempre teve alcance mais limitado do que seu uso político por grupos trotskistas, que fundamentam a necessidade da busca da revolução permanente justamente na possibilidade de que a sucessão dos meios de produção na periferia do capitalismo possa se dar de modo dinâmico e contínuo, ganhou novo impulso no campo das Relações Internacionais, talvez a disciplina acadêmica na área das Ciências Sociais cujas bases epistemológicas são mais recentes e frágeis. A partir da publicação, em 2006, do artigo Why

Ao lado do "chicote da necessidade externa", o "privilégio do atraso "aparece nos escritos de Trotsky como um mecanismo pelo qual se daria a interação entre sociedades com níveis de desenvolvimento diferentes. O privilégio do atraso histórico significa a possibilidade de as sociedades atrasadas importarem técnicas produtivas mais avançadas, combinando-as com suas estruturas sociais antigas (Trotsky, 2008: 4). 
is There no International Historical Sociology, no qual Justin Rosenberg procura mostrar que "(...)Trotsky supera os obstáculos à uma definição sociológica da internacionalidade (Rosenberg, 2006: 309)", tem crescido o debate sobre a possibilidade de que a teoria do desenvolvimento desigual e combinado possa servir de base para uma nova epistemologia geral das relações internacionais, superando os conhecidos problemas das chamadas teorias realistas, idealistas e pós-modernas que constituem as perspectivas teóricas hegemônicas nesse campo ${ }^{4}$.

A preocupação central de Rosenberg é a busca de uma teoria das relações internacionais que, por um lado, não reduza as dinâmicas domésticas a meros reflexos das interações entre os Estados e, por outro, não defina as relações entre Estados como simples ampliações das categorias utilizadas para explicar as relações internas das sociedades. Há, na percepção do autor, uma importante lacuna nas teorias sociológicas clássicas (Rosenberg, 2006, 310), abrindo espaço epistemológico para o desenvolvimento das teorias realistas, que desconectam essencialmente o campo da geopolítica do campo da sociologia, ao procurar lógicas específicas que governariam a relação entre os estados (balança de poder, interesse nacional), tomando-os como unidades coerentes de análise, em abstração das divisões e disputas presentes em cada sociedade. Assim, faltaria nas teorias sociais clássicas “(...) uma dimensão especificamente inter-societal da mudança social” (Rosenberg 2006: 312).

Para Rosenberg, o desenvolvimento desigual e combinado poderia fornecer elementos para o desenvolvimento de uma teoria sociológica da internacionalidade com base nos seguintes passos:

(...)o fenômeno da internacionalidade surge da desigualdade sócio-histórica da existência humana; suas características distintivas podem ser explicadas pela análise da condição resultante do 'desenvolvimento combinado'; e o seu significado, então redefinido sociologicamente, implica em uma reconceitualização da própria noção de desenvolvimento - que remova a raiz do problema da 'analogia doméstica' para a sociologia histórica. (Rosenberg 2006: 313)

\footnotetext{
Entre os artigos recentes no campo das Relações Internacionais que discutem os conceitos de Trotsky, destacam-se Rosenberg (2006; 2010 e 20 I3); Matin (20I3) e Selwyn (20I I, 20 I4); para uma perspectiva crítica, ver Allison e Anievas (2009); Teschke (20|4) and Rioux (20|4). Para uma primeira aproximação da teoria do desenvolvimento desigual e combinado no campo das Relações Internacionais, ver Rosenberg ( 1996).
} 
É importante notar que a ousada leitura de Trotsky proposta por Rosenberg, se, por um lado, alça o desenvolvimento desigual e combinado à condição de um pressuposto geral das relações internacionais - em substituição, por exemplo, à noção de "anarquia" entre os Estados tal como definida por Hedley Bull no clássico realista A Sociedade Anárquica -, por outro estende o conceito para muito além de seu escopo original. Em Trotsky, desenvolvimento desigual e combinado se referia, primordialmente, à forma peculiar como o modo de produção capitalista se espalhava pelo mundo, enquanto que em Rosenberg se refere ao princípio fundamental de diferenciação que dá origem às diversas sociedades e, finalmente, ao fenômeno da internacionalidade: "a internacionalidade, de modo bastante simples, (...) nada mais é do que a mais alta expressão do desenvolvimento desigual e combinado. Essa é sua definição sociológica" (Rosenberg, 2006: 328). Essa visão aparece de modo ainda mais claro no artigo publicado por Rosenberg em 2010 Basic Problems in the Theory of Uneven and Combined Development. Part II, Uneveness and Political Multiplicity, no qual o autor parte da interessante questão sobre o motivo pelo qual há diversas sociedades no mundo, e não uma apenas, para reafirmar o desenvolvimento desigual e combinado como princípio de diferenciação fundamental entre grupos políticos (Rosenberg, 2010).

Reconhecendo o caráter inovador e potencial explicativo dessa nova perspectiva teórica para o estudo das relações internacionais, cumpre, nesse momento, apontar algumas de suas arestas. Em primeiro lugar, a essencialização da categoria de desigualdade como "a lei mais geral do processo histórico" aparentemente contradiz a teleologia marxista que aponta na direção do comunismo internacional como etapa final da evolução humana. Se as relações entre sociedades têm seu fundamento na desigualdade, como pensar em um mundo pós-capitalista, em que fosse superada a luta de classes? Uma resposta provisória passaria pela especificação do conceito da desigualdade, reduzindo-o ao escopo exclusivamente histórico e inter-societal. Assim, a superação da desigualdade dos meios de produção, que seria atingida pela revolução mundial, apagaria o fundamento de diferenciação entre as sociedades, o que faria com que o mundo comunista fosse, por definição, um mundo sem Estados, formado por uma única sociedade. Essa concepção, evidentemente, tem a utilidade apenas de servir como limite crítico do 
conceito de desigualdade, definindo-o como essencial apenas com relação a sociedades baseadas na exploração do homem pelo homem, e evitando, assim, fundamentá-lo em características naturais imutáveis e meta-históricas, seja de indivíduos, de grupos humanos, ou de espaços geográficos.

Em segundo lugar, ainda com relação ao conceito de desigualdade, percebe-se uma dificuldade lógica em sua utilização positiva. Uma vez que tempo e espaço são necessariamente representados por magnitudes infinitas dadas, pois, como nota Kant na Crítica da Razão Pura, "tempos diferentes são apenas partes precisamente do mesmo tempo" e "só se pode representar um espaço uno, e quando se fala de muitos espaços entende-se com isso apenas partes de um e mesmo espaço único" (Kant, 1999, 74-78), representações definidas em termos espaço-temporais - como quaisquer relações entre objetos, indivíduos ou mesmo sociedades - são logicamente discretas, ou seja, diferentes entre si. Em outras palavras, em um dado recorte de tempo e espaço, não há jamais duas coisas iguais. Dois objetos idênticos colocados lado a lado sobre uma mesa são justamente diferentes por não estarem na mesma posição. Assim, caso o conceito de desigualdade seja entendido simplesmente como diferença, o postulado de que todos os fenômenos sociais são desiguais é absolutamente tautológico, pois, no mundo material (fenomenológico), tudo é necessariamente diferente de tudo. Como no caso da primeira dificuldade apontada, aqui a busca de uma solução teórica deve passar pela maior especificação do conceito de desigualdade, de modo a restringir seu significado. No contexto do desenvolvimento desigual e combinado, portanto, a desigualdade deve referir-se especificamente às condições materiais de produção - derivadas do nível técnico de cada sociedade, das condições naturais do lugar no espaço onde ocorre sua reprodução e da sua divisão interna do trabalho.

Em terceiro lugar, também o conceito de combinação é insuficientemente definido. Se, no sentido original apresentado por Trotsky, o caráter combinado do desenvolvimento referia-se a "um amálgama de formas arcaicas com outras mais contemporâneas" (Trotsky, 2008: 5), Rosenberg novamente amplia essa definição, entendendo o desenvolvimento combinado como a lei segundo a qual "as sociedades não se desenvolvem em isolamento" (Rosenberg, 2006: 319). Ainda assim, o significado positivo das relações mantidas pelas sociedades não é de forma alguma indicado. 
Considerando uma vez mais o tempo e o espaço como substratos de qualquer representação, a simples afirmação de que há relação entre dois fenômenos temporal e espacialmente localizados tampouco apresenta qualquer avanço no sentido do conhecimento desses fenômenos. Cumpre definir, com precisão, que forma de relação é estabelecida entre eles. Na próxima seção desse artigo, veremos como o conceito de sistema-mundo proposto por Wallerstein apresenta um passo significativo na concretização material da simples noção de combinação contida na perspectiva do desenvolvimento desigual e combinado.

Nenhuma das limitações mencionadas aponta, entretanto, para questões insolúveis, que devessem levar ao abandono da perspectiva do desenvolvimento desigual e combinado. Ao contrário, elas decorrem justamente da amplitude do significado dos conceitos envolvidos na formulação de Trotsky. O esforço teórico de especificação desses conceitos, que possibilitará sua aplicação cada vez mais frutífera a casos empíricos definidos, dependerá da capacidade dos estudiosos que vêm adotando essa perspectiva de incorporarem em suas análises outros conceitos desenvolvidos no campo do materialismo histórico.

\section{WALLERSTEIN - ANÁLISES DOS SISTEMAS-MUNDO}

A questão fundamental quando se compara "estágios" é determinar as unidades das quais os "estágios" são retratos sincrônicos (ou "tipos ideias", se preferir). E o erro fundamental da ciência social a-histórica (incluindo versões a-históricas do marxismo) é reificar as partes da totalidade como unidades desse tipo e então comparar essas estruturas reificadas.

(...)

Se vamos falar de estágios, portanto - e devemos falar de estágios -, esses devem ser estágios dos sistemas sociais, ou seja, das totalidades. E as únicas totalidades que existem ou historicamente existiram são mini-sistemas e sistemas-mundo, e, nos séculos XIX e XX, tem havido apenas um sistema-mundo, a economia-mundo capitalista.

(Wallerstein, 1974: 389-390)

A originalidade da abordagem proposta por Wallerstein para superar o problema do etapismo está, justamente, em ampliar a unidade de análise, 
dos Estados nacionais para os sistemas-mundo. Os modos de produção não seriam características de sociedades nacionais definidas, mas, ao contrário, deveriam ser comparados tendo como referência estruturas mais amplas de produção e circulação de mercadorias. Assim, com relação à América Latina, por exemplo, não haveria sentido em se falar da prevalência de modos de produção pré-capitalistas (escravistas ou feudais), mesmo que as relações de trabalho em grande medida não fossem caracterizadas pelo assalariamento dos trabalhadores, uma vez que havia clara exploração do trabalho e a produção do excedente direcionava-se, desde o início do processo de colonização, ao mercado internacional, fazendo da América latina parte da economia-mundo capitalista (Wallerstein, 1974: 399-400).

O conceito articulador da proposta teórica de análise dos sistemas-mundo é a divisão do trabalho. Um sistema-mundo caracteriza-se com referência a uma economia-mundo, portanto, como o espaço geográfico cujas cadeias de produção são interligadas, resultando em especializações regionais, o que se reflete em diferenças espaciais no tipo de trabalho realizado em cada lugar. Nas palavras de Wallerstein: “consideramos a característica definidora de um sistema social como a existência interna de uma divisão do trabalho, de modo que os vários setores ou áreas dentro dele sejam dependentes das trocas econômicas entre si (...)" (Wallerstein, 1974: 390).

Seguindo essa linha de pensamento, a integração do mundo moderno em uma única divisão internacional do trabalho ampliada, cuja forma de acumulação primordial de excedente seja por meio do metabolismo do capital em sua relação com o trabalho - o capitalismo -, faz com que estejamos diante de um único sistema-mundo, que gradualmente incorporou áreas externas para tornar-se verdadeiramente global, assumindo uma configuração que incluiu um centro dinâmico, uma semi-periferia e uma periferia. Embora formado por diversas unidades políticas, o todo constitui um sistema, por ser integrado em uma lógica de acumulação identificável, a qual, em última instância, governa as relações materiais de trabalho e produção em cada uma das partes e determina os lugares privilegiados de acumulação.

Aqui é possível encontrar um ponto de contato importante entre a teoria do desenvolvimento desigual e combinado e as análises dos sistemas-mundo. A mesma questão proposta por Rosenberg em Basic Problems in the Theory of Uneven and Combined Development. Part II, Uneveness and Political 
Multiplicity coloca-se para Wallertein, a saber, por que há o fenômeno da multiplicidade política, ou da "internacionalidade"? O problema decorre do próprio conceito de "sistema", que implica em um todo articulado, formado, não obstante, por partes diferentes entre si. As respostas oferecidas por Rosenberg e Wallerstein, entretanto, são consideravelmente distintas. Para o primeiro, a internacionalidade decorreria diretamente do princípio da "desigualdade", no sentido de que agrupamentos humanos encontraram, historicamente, condições de vida diferentes, e desenvolveram técnicas produtivas distintas (Rosenberg, 2010: 175). O contato entre esses grupos muitas vezes não foi capaz de dissolver as diferenças nos modos de vida, pois a apropriação dos modos de produção se dá de forma combinada, mantendo aspectos de novas e antigas formações sociais.

Em Wallertein, não encontramos uma formulação teórica sobre a origem da internacionalidade como fenômeno sociológico, apenas considerações sobre os motivos que impediriam o sistema-mundo moderno de tornar-se um império-mundo, embora seja constituído por uma economia-mundo de caráter global. A resposta oferecida por Wallerstein, em The Modern World System - Capitalist Agriculture and the Origins of the Europeen World-Economy in the Sixteenth Century para o problema da multiplicitade política é, sobretudo, histórica. O desenvolvimento do capitalismo como modo de produção dominante teria favorecido a criação de diferentes Estados, ao contrário do que aconteceu em economias-mundo anteriores, que tenderam à centralização política em impérios (Wallerstein, 1974: 391). A forma de acumulação capitalista de excedente apropriou-se, justamente, da competição entre unidades políticas distintas para maximizar os lucros. Esse raciocínio é posteriormente desenvolvido e ampliado por Giavanni Arrighi no primeiro capítulo do magistral $O$ Longo Século $X X$, onde o autor mostra com clareza a importância da sucessão de potências hegemônicas em um mundo politicamente fragmentado, uma vez que essas unidades políticas exerceriam a função de centro de cada um dos sucessivos ciclos de acumulação, permitindo que o capital, ao retomar sua forma financeira ao fim de cada ciclo, obtenha magnitudes sucessivamente maiores (Arrighi, 1994: 27-85).

Há aqui evidente complementaridade entre as duas perspectivas teóricas. Por um lado, a análise do sistema-mundo moderno carece de uma definição sociológica que seja capaz de explicar, em termos teóricos, o 
surgimento do fenômeno da internacionalidade. Os Estados aparecem como realidades históricas dadas, fundamentais para a atual dinâmica da economia-mundo, mas, em última análise, teoricamente exógenas. Por outro lado, a rica densidade empírica dos estudos de Wallerstein, Arrighi e Braudel ${ }^{5}$ concretizam a dinâmica prevista na teoria do desenvolvimento desigual e combinado, mostrando como, na realidade, ocorre o amalgama de "formas arcaicas com outras mais contemporâneas" a que Trotsky se referia. Em outras palavras, os estudos históricos construídos sobre a perspectiva de análise dos sistemas-mundo podem ser instrumentais para a definição do conceito de "combinação" que, como vimos, permanecia excessivamente vago na obra de Trotsky e, sobretudo, na interpretação proposta por Rosenberg, confundindo-se com a mera noção de relação entre sociedades.

As reconstruções históricas da evolução do sistema-mundo moderno permitem que o desenvolvimento combinado seja percebido, ao menos desde o século XVI, como a expansão da divisão internacional do trabalho a partir do centro europeu, de acordo com a lógica de acumulação capitalista. Mesmo quando, como propõe Rosenberg, o desenvolvimento desigual e combinado é visto como um princípio geral das relações internacionais, estendendo-se para além do escopo do mundo moderno, pode-se sugerir que o método de análise dos sistemas-mundo e de mini-sistemas a partir das cadeias de produção e troca de mercadorias, epifenômenos de divisões do trabalho internas a esses sistemas, deve fornecer elementos valiosos para a especificação das relações entre as unidades do sistema. Em resumo, as análises dos sistemas-mundo revelam um elemento fundamental à definição de "combinação" que estava faltando na perspectiva do desenvolvimento desigual e combinado - o papel da divisão inter-societal do trabalho e, como consequência, da circulação de mercadorias.

Um segundo ponto de contato que poderia ser levantado é o papel da exploração do trabalho na formação e distribuição do excedente no sistema -mundo moderno e no desenvolvimento das unidades políticas desse sistema. Dentre as várias críticas que a abordagem da análise dos sistemas-mundo provocou desde a publicação da primeira edição do seminal The Modern World System - Capitalist Agriculture and the Origins of the Europeen Worl-

Para uma interessante articulação das contribuições de Arrighi, Braudel e Wallerstein para a perspectiva teórica das análises dos sistemas-mundo ver Arienti e Filomeno (2007) 
d-Economy in the Sixteenth Century, em 1974, uma das mais importantes é a desenvolvida por Robert Brenner em The Origins of Capitalist Development: A Critique of Neo-Smithian Marxism ${ }^{6}$, de acordo com a qual a abordagem proposta por Wallerstein centra-se demasiadamente na circulação de mercadorias e insuficientemente no processo produtivo. Essa linha de argumentação fundamenta-se, sobretudo, nos três breves capítulos da Parte 2 do Livro Primeiro de $O$ Capital, onde Marx define a contradição que emerge ao se considerar que há adição de valor na simples circulação de mercadorias:

O dono do dinheiro, que aqui é ainda apenas um capitalista em forma larval, precisa comprar as mercadorias ao seu valor, vendê-las ao seu valor, e, ainda assim, ao final do processo tirar mais valor da circulação do que ele colocou em seu começo. Seu surgimento como borboleta deve, e ao mesmo tempo não deve, ter lugar na esfera da circulação. Essas são as condições do problema. (Marx, 1990: 269).

Marx avança o seu raciocínio para concluir que, em meio à esfera da circulação, há uma mercadoria capaz de gerar mais valor do que o envolvido em sua compra: o trabalho. "O dono do dinheiro encontra tal mercadoria especial no mercado: a capacidade para o trabalho, em outras palavras, a força de trabalho" (Marx, 1990: 270). A adição de valor, a produção de excedente ou a extração de mais-valia, como se queira chamar, ocorreria, portanto, no processo produtivo, e não propriamente na esfera visível da circulação. Essa perspectiva aparentemente choca-se com a abordagem de Wallerstein, para quem "trocas desiguais" teriam papel preponderante na definição da acumulação da capital em determinados espaços do sistema-mundo moderno: “(...) capitalismo não envolve apenas a apropriação da mais-valia do trabalhador pelo proprietário, mas também a apropriação do excedente de toda a economia-mundo pelas áreas centrais." (Wallerstein, 1974: 401).

Visto a partir da ótica do desenvolvimento desigual e combinado, o problema da apropriação de excedente pela circulação ou pelo processo produtivo pode ser tomado como uma síntese entre as duas hipóteses. A

6 Para uma apreciação detalhada da crítica de Brenner a Wallerstein, ver Denemark e Thomas (1988). O próprio Wallerstein reconhece a crítica de Brenner como representativa do marxismo ortodoxo no prefácio da nova edição de The Modern World System - Capitalist Agriculture and the Origins of the Europeen World-Economy in the Sixteenth Century (2011) 
extração da mais-valia se daria, no nível da produção, pela relação direta de exploração do trabalho pelos donos do capital. Nos países subdesenvolvidos, entretanto, dadas as estruturas produtivas atrasadas e com menor acumulação de capital, o valor de troca das mercadorias produzidas pelos trabalhadores em uma determinada unidade de tempo seria menor, ou, colocando em outros termos, seriam necessárias mais horas de trabalho para produzir mercadorias com valores iguais às produzidas nos países desenvolvidos, mesmo considerando-se a extração de mais valia nesses últimos. Assim, no nível da circulação internacional, haveria uma tendência à transferência de valor em direção aos países desenvolvidos, que se explicaria pelo caráter desigual e combinado das estruturas produtivas presentes em cada unidade política do sistema, e não por razões estranhas ao processo produtivo. O mérito dessa abordagem está em recolocar a exploração do trabalho e, consequentemente, a luta de classes no centro da análise sobre as desigualdades do sistema-mundo, apontando uma saída para o problema teórico das trocas desiguais prolongadas. Como observa Ben Selwyn, "sem a análise de classe, o aspecto combinado do desenvolvimento tardio e combinado se perde. E é justamente esse aspecto que contribui tão fundamentalmente para a natureza não linear e não planejada do desenvolvimento capitalista tardio." (Selwyn, 2014: 102)

\section{CONCLUSÃO - UMA TENTATIVA DE SÍNTESE}

Programas de pesquisa emergem a partir da tentativa de proteger as premissas de realizações científicas anteriores contra refutações. Os cientistas definem certo núcleo duro de postulados, os quais são aceitos por convenção. (...) Problematizações progressivas (...) resolvem anomalias por meio da introdução de teorias auxiliares, que expandem o poder explicativo dos postulados do núcleo. (...) Em outras palavras, uma defesa progressiva do núcleo duro toma a forma de um cinturão cada vez maior de teorias que aumentam o conteúdo empírico corroborado e resolvem sucessivos problemas. (...) A teoria de Trotsky sobre a Revolução Russa pode ser vista como parte de um programa de pesquisa marxista progressivo. (Burawoy, 1989: 761) 
Em um interessante e pouco conhecido artigo publicado em 1989, Michel Burawoy usa a epistemologia de Lakatos para comparar dois métodos de pesquisa em ciências sociais: o método indutivo e o método dos "programas de pesquisa". Na visão do autor, mesmo sem nunca explicitar sua metodologia, Trotsky seria um exemplo de aplicação histórica da metodologia dos programas de pesquisa, pois sua teoria do desenvolvimento desigual e combinado e sua visão política da revolução permanente cumpririam justamente a função de ampliar e fortalecer o núcleo duro dos postulados sociais, políticos e econômicos do marxismo, resolvendo anomalias históricas e acrescentando elaborações conceituais que expandem o poder explicativo das teses de Marx.

Mais especificamente, no marxismo clássico não haveria explicações convincentes para a possibilidade de a passagem do modo de produção capitalista para o socialismo começar em lugares onde as forças produtivas fossem pouco desenvolvidas, justamente porque a revolução ocorreria em função das contradições materiais entre a organização da sociedade e o desenvolvimento das forças produtivas. A Revolução Russa teria, assim, o caráter contraditório de ser, por um lado, a prova concreta de que é possível romper com o capitalismo a partir da mobilização consciente da classe trabalhadora e, por outro, um exemplo contrário à teoria marxista, segundo a qual a revolução deveria irromper primeiro nos países mais avançados, ou seja, na Inglaterra, na Alemanha ou mesmo nos Estados Unidos.

Trotsky, ao formular a teoria do desenvolvimento desigual e combinado, procura "refutar a refutação" das teses centrais do materialismo histórico, fazendo avançar o conhecimento, de acordo com concepção de Lakatos (Burawoy, 1989: 761). Rompendo com a noção de que cada Estado desenvolve-se linearmente, passando necessariamente pelo mesmo processo, que envolveria a substituição progressiva dos modos de produção até chegar ao comunismo, Trotsky sugere que as relações entre Estados geram condições complexas no que se refere à transformação das estruturas produtivas e das relações sociais, abrindo espaço para que a irrupção revolucionária ocorra em qualquer lugar onde haja a fundamental contradição entre formas sociais e políticas defasadas com relação a modos de produção mais modernos. Indo além, sua formulação teórica permite que ele preveja problemas à sustentabilidade de rupturas políticas que aconteçam sob esse signo, fazen- 
do-o postular a necessidade de que a revolução se expanda até tornar-se permanente. Nas palavras de Trotsky:

O internacionalismo não é um princípio abstrato, mas um reflexo teórico e político do caráter da economia mundial [poderse-ia dizer, aqui, da economia-mundo], do desenvolvimento mundial das forças produtivas, e da escala mundial da luta de classes. A revolução socialista começa no nível nacional. Mas ela não pode completar-se nesse nível. (Trotsky, 2011: XXXV - observação entre colchetes minha)

A perspicaz análise de Tortsky sobre a dinâmica internacional do capitalismo, nesse texto de 1931, adianta muitos dos aspectos da contribuição de Wallerstein, que surgiria mais de quarenta anos depois. Aqui, vê-se que classes sociais não devem ser definidas em termos nacionais (Wallertein, 2011: 23), e que a mudança revolucionária dos meios de produção não é possível caso centrada em apenas uma unidade política do sistema. Em contrapartida, como vimos, a perspectiva das análises dos sistemas-mundo acrescenta à teoria do desenvolvimento desigual e combinado aspectos fundamentais não definidos por Trotsky, como o papel central da divisão do trabalho para a definição das características concretas da economia-mundo, o que possibilita a positivação de categorias como "desigualdade" e "combinação", que permaneciam excessivamente amplas na formulação de Trotsky e, sobretudo, em suas leituras acadêmicas contemporâneas. Ao fazer isso, Wallerstein adiciona sua própria contribuição ao programa de pesquisa materialista histórico, adensando os aspectos teóricos relacionados ao problema da multiplicidade política nas transformações do sistema-mundo moderno. Dialeticamente, a leitura contemporânea do desenvolvimento desigual e combinado também contribui para o desenvolvimento teórico das análises dos sistemas-mundo, ao indicar uma forma de reintroduzir o papel da produção e da exploração do trabalho na explicação das tendências de concentração de capital em determinadas unidades políticas do sistema.

De posse dos conceitos propostos por Trotsky, expostos e problematizados na primeira seção desse texto, bem como dos fundamentos da perspectiva teórica de Wallertein, apresentados na segunda seção, e considerando a abordagem epistemológica sugerida por Burawoy, podemos, agora, como conclusão desse breve artigo, arriscar uma síntese dos postulados do materia- 
lismo histórico, combinando o núcleo duro, derivado das teses de Marx, com as contribuições advindas do desenvolvimento desigual e combinado e das análises dos sistemas-mundo. A síntese proposta mantém a centralidade do processo de produção, e, ao mesmo tempo, integra ao materialismo histórico a perspectiva internacionalista, ao definir a importância da multiplicidade política, sistematicamente organizada em uma economia-mundo, para a evolução material da história:

A produção de valor se dá a partir do trabalho; a organização do trabalho e sua relação específica com o capital definem modos de produção; a história é caracterizada pela sucessão de modos de produção; surgiram, historicamente, uma multiplicidade de unidades políticas, em função das desigualdades dos modos de produção entre diferentes regiões, expressa no princípio da desigualdade; as unidades políticas definem-se desde as suas origens por relações materiais com outras unidades, por meio de trocas e guerras, produzindo como consequência a divisão espacial e especialização material do trabalho; ao definir-se uma economia-mundo, em função da divisão do trabalho, um modo de produção torna-se preponderante, embora ele não se manifeste de forma homogênea em todas as unidades políticas que passam então a compor o sistema-mundo; rupturas políticas com o objetivo consciente de transformar o modo de produção preponderante no sistema -mundo podem surgir em qualquer das unidades políticas do sistema, em especial naquelas em que haja forte contradição entre o modo de produção e estruturas sociais herdadas de modos de produção anteriores; as rupturas em unidades políticas isoladas não provocam necessariamente a mudança do modo de produção do sistema-mundo, contudo podem expandir-se em revoluções permanentes.

\section{THE PROBLEM OF POLITICAL MULTIPLICITY FOR HIS- TORICAL MATERIALISM: INSIGHTS FROM WORLD-SYSTEM ANALYSIS AND UNEVEN AND COMBINED DEVELOPMENT}

\section{Abstract}

World-system analysis and the theory of uneven and combined development are two of the most insightful and innovative theoretical 
perspectives for the study of Global Political Economy within the historical materialist research program. In the founding texts of each of these perspectives, Trotsky and Wallerstein face the same question: how to overcome stage approaches of development, derived from 'vulgar Marxism', which stated the impossibility of the outburst of socialist revolutions in countries with backward productive structures in relation to central capitalist States. By different paths, Trotsky and Wallerstein refuse this approach. Trotsky suggests that modes of production in backward countries assume an uneven and combined character; Wallestein suggests a holistic perspective of development, in which modes of production appear in reference to the world-economy. In both cases, it is possible to identify the underlying problem posited by the fact of political multiplicity, as capitalism actually did not spread evenly across different countries. In this article I claim to identify the underlying problem posited by the fact of political multiplicity, as capitalism effectively did not spread evenly across different states. In this article I claim that, despite the substantial differences between those two perspectives, Trotsky's and Wallerstein's contributions can be regarded as complimentary, inasmuch as they broaden the explanatory power of historical materialism.

Keywords: Uneven and Combined Development - Permanent Revolution - World-System Analysis - World-economy - Historical Materialism - Stages of development - León Trotsky - Immanuel Wallerstein.

JEL Classification: F59; B51.

\section{REFERÊNCIAS}

São minhas as traduções de todos os trechos citados cuja referência original esteja em inglês.

ALLISON, J. \& ANIEVAS, A. The uses and misuses of uneven and combined development: an anatomy of a concept. Cambridge Review of International Affairs,22:1,47 - 67, 2009 
ARIENTI, W. \& FILOMENO F. Economia politica do moderno sistema mundial: as contribuições

de Wallerstein, Braudel e Arrighi. Ensaios FEE, Porto Alegre, v. 28, n. 1, p. $99-126.2007$

ARRIGHI, G. O Longo Século XX. Rio de Janeiro: Contraponto, 1996

BRENNER, R. The Origins of Capitalist Development: A Critique of NeoSmithian Marxism. New Left Review 104: 25-92, 1977

BULL, H. A Sociedade Anárquica. São Paulo: IPRI, 2002

BURAWOY, M. Two Methods in Search of Science: Skocpol versus Trotsky. Theory and Society, Vol. 18, No. 6, pp. 759-805, 1989

DENEMARK, R. \& THOMAS, K. The Brenner-Wallerstein Debate. International Studies Quarterly, Vol. 32, No. 1, pp. 47-65, 1988

KANT, I. Crítica da Razão Pura. São Paulo: Nova Cultura, 1999.

MARX, K. Capital, vol I. London: Penguin, 1990

MATIN, K. Redeeming the Universal: Postcolonialism and the Inner Life of Eurocentrism. European Journal of International Relations 19, no. 2 : 353-77. 2013.

RIOUX, S. Mind the (Theoretical) Gap: On the Poverty of International Relations Theorising of Uneven and Combined Development. Global Society 1-29, 2014.

ROSENBERG, J. Isaac Deutscher and the Lost History of International Relations. New Left Review, I, , no. 215 (February): 3-15, 1996.

ROSENBERG, J. Why is There no international historical sociology? European Journal of International Relations 12(3): 307-340, 2006. 
ROSENBERG, J. Basic problems in the theory of uneven and combined development. Part II: Unevenness and political multiplicity. Cambridge Review of International Affairs 23(1): 165-189, 2010.

ROSENBERG, J. Kenneth Waltz and Leon Trotsky: Anarchy in the mirror of uneven and combined development. International Politics Vol. 50, 2, 183-230, 2013.

Teschke, Benno. "IR Theory, Historical Materialism, and the False Promise of International Historical Sociology.” Spectrum: Journal of Global Studies 6, no. 1 (May 2014): 1-66.

SELWYN, B. Trotsky, Gerschenkron and the Political Economy of Late Capitalist Development. Economy and Society, 40 (3): 421- 50, 2011.

SELWYN, B. Global development crisis. London: Polity, 2014.

STALIN, J. Sobre o materialismo dialético e o materialismo histórico, 1938. Marxists.org. Disponível em: http://www.marxists.org/portugues/ stalin/1938/09/mat-dia-hist.htm, acesso em 01/08/2014.

TESCHKE, B. IR Theory, Historical Materialism, and the False Promise of International Historical Sociology. Spectrum: Journal of Global Studies 6, no. 1 1-66. 2014.

TROTSKY, L. Balanço e perspectivas, 1906. Marxists.org. Disponível em: https:/www.marxists.org/portugues/trotsky/1906/balanco/index.htm, acesso em 28/07/2014 .

TROTSKY, L. History of the Russian Revolution. Chicago: Haymarket, 2008.

TROTSKY, L. The Permanent Revolution. Kapaau: Gutenberg 2011. 
WALLERSTEIN, I. The Rise and Future Demise of the Wolrd Capitalist System, Concepts for a Comparative Analysis. Comparative studies in society and history. Volume 16, Issue 4, 387-415, 1974.

WALLERSTEIN, I. The Modern World System I - Capitalist Agriculture and the Origins of the Europeen World-Economy in the Sixteenth Century. Los Angeles: University of California, 2011. 